\title{
PENGARUH KOMPOSISI MEDIA TANAM DAN PENUTUPANPARANET TERHADAP PERTUMBUHAN SENGON (Paraserianthes falcataria (L.)Nielsen)
}

(The Effect Of Plant Media Composition And Paranet Closure On The Growth Of Sengon (Paraserianthes falcataria (L.) Nielsen))

\author{
Muhammad Syahrul Eka Prakasa ${ }^{1}{ }$, Joko Triwanto $^{1}$, Tatag Muttaqin ${ }^{1}$ \\ ${ }^{1}$ Jurusan Kehutanan, Fakultas Pertanian-Peternakan Universitas \\ Muhammadiyah Malang Jalan Raya Tlogomas No.246, Tlogomas, Malang, JawaTimur \\ 65144. \\ *Email : eka.prakasa.ep@gmail.com
}

\begin{abstract}
Sengon or (P. falcataria (L.) Nielsen). including the Leguminoceae family. This plant is very potential to be selected as one of the fast growing species, the management is relatively easy, the wood is strong and the market demand continues to increase, while ecologically Sengon can improve environmental quality such as increasing soil fertility and improving water systems. . The purpose of this research was to determine the composition of a good and correct planting medium in order to obtain maximum plant growth and to determine the effect of seedling cover treatment with paranet on the growth of sengon ( $P$. falcataria (L.) Nielsen). The study was conducted at the Forestry Laboratory of the Faculty. Agriculture-Animal Husbandry University of Muhammadiyah Malang. Observations were made from January to April 2019. This study used a randomized block mix (RAK) which was arranged factorial. The first factor was the composition of the planting medium $(P)$ consisting of 4 levels of top soil and sand media with a ratio of 1: 1 (control), and media for top soil, sand and manure (chicken, goat and cow), with each treatment the ratio was 2: 1: 1. The second factor was paranet cover treatment (M) which consisted of 3 levels of plants without getting paranet cover treatment, plants were treated with paranet cover with a density of $25 \%$ and $50 \%$. The variables observed were germination rate, germination rate, seedling growth (diameter, height, number of leaves, wet weight, dry weight, and root length). If the results of the analysis have a significant effect, it will be further tested using the Duncan 5\% test. The results of this study indicated that there was no significant interaction with the percentage of germination between the composition of the growing medium and the light intensity treatment on the germination rate variable of sengon ( $P$. falcataria (L.) Nielsen) seedlings. The best treatment of this research is that there is a significant interaction between the composition of the growing media and the treatment of light intensity on the height variable of sengon seedlings ( $P$. falcataria (L.) Nielsen). Topsoil, sand, and goat manure with a ratio of 2: 1: 1 is the most suitable and good planting medium for the growth of sengon (P. falcataria (L.) Nielsen) seedlings. Plant treatment without paranet cover was a good treatment and had a positive effect on the growth of sengon (P. falcataria (L.) Nielsen) seedlings.
\end{abstract}

Keywords : Light Intensity, Manure, Randomized Block Design, Sengon 


\section{JOURNAL OF FOREST SCIENCE AVICENNIA}

E-ISSN : 2622-8505 | Email : avicennia.kehutananumm@umm.ac.id http://ejournal.umm.ac.id/index.php/avicennia

○ Jl. Raya Tlogomas No.246 Malang, Jawa Timur 0822-5785-2386 (Febri)

\section{Intisari}

Sengon atau (P. falcataria (L.) Nielsen). termasuk famili Leguminoceae. Tanaman ini sangat potensial untuk dipilih sebagai salah satu kayu cepat tumbuh (fast growing species), pengelolaan relatif mudah, sifat kayunya termasuk kelas kuat dan permintaan pasar yang terus meningkat, sedangkan secara ekologis Sengon dapat meningkatkan kualitas lingkungan seperti meningkatkan kesuburan tanah dan memperbaiki tata air. Tujuan dari dilakukannya penelitian ini adalah untuk mengetahui komposisi media tanam yang baik dan benar supaya mendapatkan pertumbuhan tanaman yang maksimal dan mengetahui pengaruh dari perlakuan penutupan semai dengan paranet terhadap pertumbuhan sengon ( $P$. falcataria (L.) Nielsen).Penelitian dilaksanakan di Laboratorium Kehutanan Fakultas Pertanian-Peternakan Universitas Muhammadiyah Malang. Pengamatan dilakukan dari bulan Januari - April 2019. Penelitian ini menggunakan Racangan Acak Kelompok (RAK) yang disusun secara faktorial. Faktor pertama komposisi media tanam (P) yang terdiri dari 4 level media top soil dan pasir dengan perbandingan 1:1 (kontrol), dan media top soil, pasir dan pupuk kandang (ayam, kambing dan sapi), dengan tiap perlakuan perbandingannya 2:1:1. Faktor kedua perlakuan penutupan paranet (M) yang terdiri dari 3 level tanaman tanpa mendapatkan perlakuan penutupan paranet, tanaman mendapatkan perlakuan penutupan paranet dengan kerapatan $25 \%$ dan $50 \%$. Peubah yang di amati yaitu daya perkecambahan, laju perkecambahan, pertumbuhan semai (diameter, tinggi, jumlah daun, bobot basah, bobot kering, dan panjang akar). Apabila hasil analisisnya berpengaruh nyata akan diuji lanjut menggunakan uji Duncan $5 \%$. Hasil penelitian ini menunjukkan bahwa tidak terjadi interaksi yang nyata terhadap presentase perkecambahan antara komposisi media tanam dan perlakuan intensitas cahaya pada peubah laju perkecambahan semai sengon ( $P$. falcataria (L.) Nielsen). Perlakuan terbaik dari penelitian ini yaitu terjadi interaksi yang nyata antara komposisi media tanam dan perlakuan intensitas cahaya pada peubah tinggi semai sengon ( $P$. falcataria (L.) Nielsen). Media tanam topsoil, pasir, dan pupuk kandang kambing dengan perbandingan 2:1:1 merupakan media tanam yang paling sesuai dan baik untuk pertumbuhan semai sengon ( $P$. falcataria (L.) Nielsen). Perlakuan tanaman tanpa mendapatkan penutupan paranet merupakan perlakuan yang baik dan berpengaruh positif terhadap pertumbuhan semai sengon ( $P$. falcataria (L.) Nielsen).

Kata Kunci : Intensitas Cahaya, Pupuk Kandang, Rancangan Acak Kelompok, Sengon

\section{PENDAHULUAN}

Sengon atau (Paraserianthes falcataria (L.) Nielsen) termasuk famili Leguminoceae. Tanaman ini sangat potensial untuk dipilih sebagai salah satu kayu cepat tumbuh (fast growing species), pengelolaan relatif mudah, sifat kayunya termasuk kelas kuat dan permintaan pasar yang terus meningkat, sedangkan secara ekologis Sengon dapat meningkatkan kualitas lingkungan seperti meningkatkan kesuburan tanah dan memperbaiki tata air (Nugroho, 2015).

Pertumbuhan pada suatu tanaman dapat diukur serta dapat dinyatakan dengan angka atau bersifat kuantitatif. Dijelaskan oleh Suharti (2008), bahwa pertumbuhan pada tanaman tidak terlepas oleh adanya faktor-faktor yang mempengaruhi baik itu faktor internal maupun faktor eksternal. Faktor internal merupakan faktor yang berasal dari tubuh 


\section{JOURNAL OF FOREST SCIENCE AVICENNIA}

E-ISSN : 2622-8505 | Email : avicennia.kehutananumm@umm.ac.id http://ejournal.umm.ac.id/index.php/avicennia

Pl. Raya Tlogomas No.246 Malang, Jawa Timur 0822-5785-2386 (Febri)

tumbuhan itu sendiri seperti faktor genetik dan hormon. Faktor eksternal merupakan faktor yang berasal dari luar tubuh tumbuhan tersebut yaitu dari

\section{METODE PENELITIAN}

\section{Waktu dan Tempat Penelitian}

Penelitian dilakukan dari bulan Januari - April 2019 dan dilaksanakan di Perumahan IKIP Tegalgondo Blok 1-C Malang, dan Laboratorium Kehutanan Fakultas Pertanian - Peternakan Universitas Muhammadiyah Malang.

\section{Metode Pengambilan Data}

Metode pengambilan data yang dibutuhkan dalam penelitian ini yaitu dengan menggunakan Rancangan Acak Kelompok (RAK) yang terdiri dari 2 Faktorial, apabila hasil analisisnya berpengaruh nyata akan diuji lanjutmenggunakan uji Duncan 5\%.

\section{Metode Analisis Data}

Penelitian ini menggunakan Rancangan Percobaan Kelompok (RAK) dengan dua faktor yang disusun secara faktorial. Faktor pertama yaitu komposisi media (P) terdiri dari empat level dan faktor kedua yaitu penutupan paranet (M) yang terdiri dari tiga level. Faktor percobaan tersebut antara lain faktor I = Komposisi media, komposisi media nya yaitu P1 = Media top soil dan pasir (Kontrol), P2 = Media top soil, pasir dan pupuk kandang (ayam) dengan perbandingan $2: 1: 1, \mathrm{P} 3=$ Media top soil, pasir dan pupuk kandang (kambing) dengan perbandingan 2:1:1, P4 = Media top soil, pasir dan pupuk kandang (sapi) denganperbandingan 2:1:1. Faktor II = Penutupan Paranet, terdiri dari 3 perlakuan antara lain, M1 = Tanaman tanpa mendapatkan penutupan paranet, $\mathrm{M} 2=$ Tanaman mendapatkan perlakuan penutupan paranet dengan kerapatan 25\%, M3 = Tanaman mendapatkan perlakuan penutupan paranet dengan kerapatan lingkungan. Faktor eksternal yang mempengaruhi pertumbuhan meliputi cahaya, ketersediaan nutrisi, air, kelembapan, suhu.

$50 \%$. Masing-masing perlakuan diulang 3 kali, sehingga terdapat $4 \times 3 \times 3=36$ unit percobaan.

\section{HASIL DAN PEMBAHASAN}

\section{Tinggi Tanaman}

Berdasarkan hasil penelitian yang didapat bahwa terjadinya pengaruh yang sangat nyata antara kombinasi perlakuan komposisi media tanam ( $P$ ) dan perlakuan intensitas cahaya (M) terhadap tinggi semai sengon (Paraserianthes falcataria (L.) Nielsen) pada pengamatan ke 1, 2, 3, 4, $5,8,9$, dan ke 10 minggu setelah tanam, terjadi pengaruh yang nyata pada pengamatan ke 6 dan ke 7 minggu setelah tanam. Untuk mengetahui kombinasi perlakuan dari komposisi media tanam (P) dan perlakuan intensitas cahaya (M) dilakukan uji Duncan dengan taraf $a=0,05$ yang disajikan pada Tabel 1 .

Tabel 1 Menunjukkan bahwa hasil rerata interaksi paling tinggi hingga akhir pengamatan ditunjukkan oleh kombinasi perlakuan komposisi media tanam top soil, pasir, pupuk kandang kambing dan tanaman tanpa mendapatkan perlakuan penutupan paranet (P3M1) dengan nilai tinggi semai $13,58 \mathrm{~cm}$, secara statistik tidak berbeda nyata dengan kombinasi perlakuan (P4M1). Rerata interaksi paling rendah hingga akhir pengamatan ditunjukkan oleh kombinasi perlakuan komposisi media tanam topsoil, pasir, pupuk kandang ayam dan tanaman mendapatkan perlakuan penutupan paranet dengan kerapatan 50\% (P2M3) dengan nilai tinggi semai $7,96 \mathrm{~cm}$, secara statistik tidak berbeda nyata dengan kombinasi perlakuan ( $P$ 1M1), (P1M2), dan (P4M2). Hal ini di jelaskan juga menurut pendapat 


\section{JOURNAL OF FOREST SCIENCE AVICENNIA}

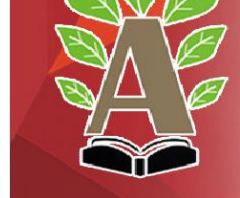

E-ISSN : 2622-8505 | Email : avicennia.kehutananumm@umm.ac.id http://ejournal.umm.ac.id/index.php/avicennia

Pl. Raya Tlogomas No.246 Malang, Jawa Timur 0822-5785-2386 (Febri)

Samekto, "pupuk kandang tidak hanya mengandung unsur makro seperti Nitrogen (N), Fosfat (P), dan Kalium (K), namun pupuk kandang juga mengandung unsur mikro sepert Kalsium (Ca), Magnesium (Mg), dan Mangan (Mn) yang dibutuhkan tanaman untuk proses bertumbuh serta berperan memelihara keseimbangan hara dalam tanah, karena pupuk kandang berpengaruh untuk jangka waktu yang lama dan merupakan gudang makanan bagi tanaman" (Samekto, 2006).

\section{Jumlah Daun Semai}

Berdasarkan hasil penelitian yang didapat bahwa terjadinya pengaruh yang sangat nyata antara kombinasi perlakuan komposisi media tanam ( $\mathrm{P})$ dan perlakuan penutupan paranet (M) terhadap jumlah daun semai sengon ( $P$. falcataria (L.) Nielsen) pada pengamatan ke $31,37,49,55,61$, $67,73,79$, dan ke 85 hari setelah semai, tidak terjadi pengaruh pada pengamatan ke 43 hari setelah semai. Untuk mengetahui kombinasi perlakuan dari komposisi media tanam dan perlakuan penutupan paranet dilakukan uji Duncan dengan taraf $a=0,05$ yang disajikan pada Tabel 1.

Tabel 1 menunjukkan bahwa hasil rerata interaksi paling banyak hingga akhir pengamatan ditunjukkan oleh kombinasi perlakuan komposisi media tanam top soil, pasir, pupuk kandang kambing dan tanaman tanpa mendapatkan perlakuan penutupan paranet (P3M1) dengan jumlah daun sebanyak 35 daun, secara statistik tidak berbeda nyata dengan kombinasi perlakuan komposisi media tanam top

\section{Diameter}

Berdasarkan hasil penelitian yang didapat menunjukkan bahwa kombinasi antara perlakuan komposisi media tanam (P) dan perlakuan penutupan paranet $(M)$ terjadi pengaruh yang sangat nyata pada pengamatan ke $31,37,49,55,61,67,73,79$ dan ke 85 soil, pasir, pupuk kandang sapi dan tanaman tanpa mendapatkan perlakuan penutupan

paranet (P4M1) dengan jumlah daun sebanyak 35 daun. Rerata interaksi paling sedikit terdapat pada kombinasi perlakuan komposisi media tanam topsoil, pasir dan tanaman mendapatkan perlakuan penutupan paranet dengan kerapatan 50\% (P1M3) dengan jumlah daun sebanyak 17 daun, secara statistik tidak berbeda nyata dengan kombinasi perlakuan komposisi media tanam top soil, pasir dan tanaman mendapatkan penutupan paranet dengan kerapatan $25 \% \quad$ (P1M2) dengan jumlah daunsebanyak 18 daun. Menurut Mas'ud, (2009) "tingginya kandungan Nitrogen (N) memacu peningkatan jumlah daun tanaman di bandingkan pupuk buatan lainnya. Fungsi nitrogen merangsang pertumbuhan tanaman dan memberikan warna hijau pada daun. Nitrogen lebih banyak terdapat pada bagian jaringan muda di bandingkan jaringan tua tanaman, terutama terakumulasi pada daun dan biji". Seperti yang dijelaskan Lakitan (1996), "Setiap tanaman memiliki kemampuan yang berbeda - beda, beberapa jenis tanaman mampu tumbuh dan berkembang dengan baik bila ternaungi dengan batas tertentu. Tanaman yang ternaungi menunjukkan laju fotosintesis sangat rendah pada intensitas cahaya yang tinggi", seperti data yang di dapat menunjukkan tanaman yang tumbuh dan berkembang dengan baik yaitu tanaman yang mendapat perlakuan tanpa penutupan paranet.

hari setelah semai. Terjadi pengaruh yang nyata antara kombinasi perlakuan komposisi media tanam (P) dan perlakuan penutupan paranet (M) pada pengamatan ke 43 hari setelah semai. Untuk mengetahui perbedaan kombinas dari komposisi media tanam dan penutupan paranet dilakukan uji Duncan 


\section{JOURNAL OF FOREST SCIENCE AVICENNIA}

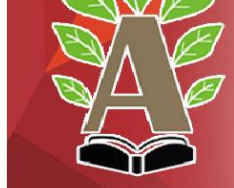

E-ISSN : 2622-8505 | Email : avicennia.kehutananumm@umm ac.id http://ejournal.umm.ac.id/index.php/avicennia

Pl. Raya Tlogomas No.246 Malang, Jawa Timur 0822-5785-2386 (Febri)

dengan taraf $\mathrm{a}=0,05$ yang disajikan pada Tabel 1.

Tabel 1 menunjukkan bahwa hasil rerata paling besar hingga akhir pengamatan ditunjukkan oleh kombinasi perlakuan komposisi media tanam top soil, pasir, pupuk kandang sapi dan tanaman tanpa mendapatkan perlakuan penutupan paranet (P4M1) dengan nilai diameter $2,1 \mathrm{~mm}$, secara statistik tidak berbeda nyata dengan kombinasi perlakuan komposisi media tanam top soil, pasir, pupuk kandang kambing dan tanaman tanpa mendapatkan perlakuan penutupan paranet (P3M1) dengan nilai diameter sebesar 2,0 mm. Rerata interaksi paling kecil hingga akhir pengamatan di tunjukkan oleh kombinasi perlakuan komposisi media tanam topsoil, pasir, dan tanaman mendapatkan perlakuan penutupan paranet dengan kerapatan 25\% (P1M2) dengan nilai diameter sebesar 0,96 mm, secara statistik tidak berbeda nyata dengan kombinasi perlakuan (P1M3), (P2M3),(P3M2), (P3M3), (P4M2), (P4M3. Seperti yang dijelaskan Hartatik (2004), "Tekstur dari pupuk kandang kambing berbentuk butiran - butiran yang agak sukar dipecah secara fisik sehingga sangat berpengaruh terhadap proses dekomposisi dan proses penyediaan haranya, kadar hara pupuk kandang kambing mengandung kalium yang lebih tinggi dari pupuk kandang lainnya, sementara untuk kandungan unsur $\mathrm{N}$ dan $P$ hampir sama dengan pukan lainnya". Sesuai dengan pendapat Haryadi (1980) yang menyatakan bahwa pertambahan lingkaran batang berkayu merupakan hasil pertumbuhan meristem samping. Pada tanaman yang mengalami pertumbuhan sekunder proses pemanjangan batang segera diikuti oleh perkembangan kambium sehinga terjadi perbesaran dari batang tanaman.

\section{Bobot Basah, Bobot Kering, Panjang Akar}

Berdasarkan hasil penelitian yang didapat bahwa terjadinya pengaruh yang sangat nyata antara kombinasi perlakuan komposisi media tanam (P) dan perlakuan intensitas cahaya (M) terhadap bobot basah dan bobot kering semai sengon ( $P$. falcataria (L.) Nielsen). Sedangkan hasil yang didapat menunjukkan bahwa terjadinya pengaruh yang sangat nyata antara kombinasi perlakuan komposisi media tanam ( $P$ ) dan perlakuan intensitas cahaya (M) terhadap panjang akar semai sengon ( $P$. falcataria (L.) Nielsen). Untuk mengetahui kombinasi perlakuan dari komposisi media tanam dan perlakuan penutupan paranet dilakukan uji Duncan dengan taraf $a=0,05$ yang disajikan pada Tabel 1.

Tabel 1 menunjukkan bahwa hasil rerata bobot basah semai terberat ditunjukkan oleh kombinasi perlakuan komposisi media tanam topsoil, pasir, pupuk kandang kambing dan tanaman tanpa mendapatkan perlakuan penutupan paranet (P3M1) dengan nilai bobot basah 1,80 gr, secara statistik tidak berbeda nyata dengan kombinasi perlakuan komposisi media tanam top soil, pasir, pupuk kandang sapi dan tanaman tanaman tanpa mendapatkan perlakuan penutupan paranet (P4M1) dengan nilai bobot basah 1,73 gr. Untuk hasil rerata bobot kering semai terberat ditunjukkan oleh kombinasi perlakuan komposisi media tanam topsoil, pasir, dan pupuk kandang sapi dan tanaman tanpa mendapatkan perlakuan penutupan paranet (P4M1) dengan nilai bobot kering 0,57 gr, secara statistik tidak berbeda nyata dengan kombinasi perlakuan komposisi media tanam top soil, pasir, pupuk kandang kambing dan tanaman tanpa mendapatkan perlakuan penutupan paranet (P3M1) dengan nilai bobot basah 0,54 gr. Syekhfani (2002), menyatakan bahwa dengan pemberian 


\section{JOURNAL OF FOREST SCIENCE AVICENNIA}

E-ISSN : 2622-8505 | Email : avicennia.kehutananumm@umm.ac.id http://ejournal.umm.ac.id/index.php/avicennia

○ Jl. Raya Tlogomas No.246 Malang, Jawa Timur 0822-5785-2386 (Febri)

pupuk organik, unsur hara yang tersedia dapat diserap tanaman dengan baik karena itulah pertumbuhan daun lebih lebar dan fotosintesis terjadi lebih banyak. Hasil fotosintesis inilah yang digunakan untuk membuat sel-sel batang, daun dan akar sehingga dapat mempengaruhi bobot basah tersebut.

Hasil rerata panjang akar semai terpanjang ditunjukkan oleh kombinasi perlakuan komposisi media tanam topsoil, pasir, dan pupuk kandang kambing dan tanaman tanpa mendapatkan perlakuan penutupan paranet (P3M1) dengan nilai $6,84 \mathrm{~cm}$, secara statistik tidak berbeda nyata dengan kombinasi perlakuan komposisi media tanam top soil, pasir, pupuk kandang sapi dan tanaman tanpa mendapatkan perlakuan penutupan paranet (P4M1) dengan nilai $6,71 \mathrm{~cm}$. Suhu yang disebabkan oleh cahaya yang menyinari media mampu mempengaruhi proses transpirasi tanaman sehingga memicu akar untuk tumbuh lebih panjang dalam mencari asupan air guna mencukupi kadar air dan sebagai pengangkut zat makanan. Faktor penghambat pertumbuhan akar tanaman adalah kepadatan tanah di lapisan bawah yang tinggi, biasanya diukur dari tingginya berat isi tanah. Pada umumnya berat isi tanah semakin meningkat dengan meningkatnya kedalaman tanah, seiring dengan semakin rendahnya kandungan bahan organik tanah, aktivitas perakaran, biota, dan kandungan liat tanah (Lal dan Greenland, 1979).

Tabel 1. Rerata Terbaik Hingga Akhir Kombinasi Perlakuan Komposisi Media Tanam (P) dan Perlakuan Penutupan Paranet (M).

\begin{tabular}{cccccc}
\hline $\begin{array}{c}\text { Tinggi } \\
(\mathrm{cm})\end{array}$ & $\begin{array}{c}\text { Jumlah } \\
\text { Daun }\end{array}$ & $\begin{array}{c}\text { Diameter } \\
(\mathrm{cm})\end{array}$ & $\begin{array}{c}\text { Berat } \\
\text { Basah } \\
(\mathrm{gr})\end{array}$ & $\begin{array}{c}\text { Berat } \\
\text { Kering } \\
(\mathrm{gr})\end{array}$ & $\begin{array}{c}\text { Panjang } \\
\text { Akar } \\
(\mathrm{cm})\end{array}$ \\
\hline $13,5 \mathrm{i}$ & $35 \mathrm{k}$ & $2,1 \mathrm{f}$ & $1,80 \mathrm{j}$ & $0,57 \mathrm{~g}$ & $6,84 \mathrm{j}$ \\
$(\mathrm{P} 3 \mathrm{M} 1)$ & $(\mathrm{P} 3 \mathrm{M} 1)$ & $(\mathrm{P} 4 \mathrm{M} 1)$ & $(\mathrm{P} 3 \mathrm{M} 1)$ & $(\mathrm{P} 4 \mathrm{M} 1)$ & $(\mathrm{P} 3 \mathrm{M} 1)$ \\
\hline
\end{tabular}

\section{Kesimpulan}

Kesimpulan yang diperoleh dari hasil penelitian ini adalah sebagai berikut : Terjadi interaksi yang sangat nyata terhadap parameter tinggi, jumlah daun, dan diameter semai sengon ( $P$. falcataria (L.) Nielsen). Pengukuran tinggi semai tertinggi terdapat pada kombinasi perlakuan (P3M1). Pengukuran jumlah daun terbanyak terdapat pada kombinasi perlakuan (P3M1). Pengukuran diameter terbesar terdapat pada kombinasi perlakuan (P4M1). Media tanam topsoil, pasir, dan pupuk kandang kambing (P3) dengan perbandingan 2:1:1 merupakan media tanam yang paling sesuai dan baik untuk pertumbuhan semai sengon ( $P$. falcataria (L.) Nielsen). Perlakuan tanaman tanpa mendapatkan perlakuan penutupan paranet merupakan perlakuan yang baik dan berpengaruh positif terhadap pertumbuhan semai sengon ( $P$. falcataria (L.) Nielsen).

\section{Saran}

Berdasarkan hasil penelitian yang telah dilakukan, peneliti menyarankan bahwa perlu dilakukan penelitian lebih lanjut mengenai Pengaruh Komposisi Media Tanam dan Penutupan Paranet terhadap Pertumbuhan Sengon ( $P$. falcataria (L.) Nielsen) supaya pembubidayaan tanaman sengon laut bisa diperluas kembali, dengan harapan pelestarian tanaman kehutanan khusus nya sengon laut, karena untuk saat ini kurangnya perhatian terhadap pelestarian tanaman kehutanan, perlu juga kesadaran masyarakat untuk turut serta dalam pengelolaannya. 


\section{JOURNAL OF FOREST SCIENCE AVICENNIA}

E-ISSN : 2622-8505 | Email : avicennia.kehutananumm@umm.ac.id http://ejournal.umm.ac.id/index.php/avicennia

O Jl. Raya Tlogomas No.246 Malang, Jawa Timur 0822-5785-2386 (Febri)

\section{DAFTAR PUSTAKA}

Hartatik, W. Dan Widowati, L. R. 2004. Pupuk Kandang. Bogor. Institut Pertanian Bogor.

Haryadi. 1980. Pengantar Agronomi. PT Gramedia. Jakarta.

Lakitan, B. 1996. Fisiologi Pertumbuhan dan Perkembangan Tanaman. P.T. Grafindo Persada. Jakarta.

Lal, R. and D. J. Greenland. 1979. Soil physic properties and crop production in the tropic. John Willey and Sons, Ltd, New York.

Mas'ud, H. 2009. Sistem Hidroponik dengan Nutrisi dan Media Tanam Berbeda Terhadap Pertumbuhan dan Hasil Selada. Media Litbang Sulteng. 2 (2): 131-136.

Nugroho, T.A. dan Z. Salamah. 2015. Pengaruh Lama Perendaman dan Konsentrasi Biji Sengon (Paraserianthes falcataria L.). JUPEMASI-PBIO, Vol. 9 No. 3. Bibit Sengon (Paraserianthes falcataria(L.). Jurnal Penelitian Hutan dan Konservasi Alam. Vol. $\checkmark$ no. 1.

Samekto, Riyo. 2006. Pupuk Kompos. PT. Citra Aji Parama. Yogyakarta

Suharti. 2008. Aplikasi Inokulum EM-4 dan Pengaruhnya Terhadap Pertumbuhan Bibit Sengon (Paraserianthes falcataria (L.). Jurnal Penelitian Hutan dan Konservasi Alam. Vol. $V$ no. 1.

Syekhfani. 2002. Arti penting bahan organik bagi kesuburan tanah. Jurnal Penelitian Pupuk Organik 